Article

\title{
The Vulnerable (Post) Modern Self and the "Greening" of Spiritual Personhood through Life in the Spirit
}

\author{
Mary Frohlich $\mathbb{D}$ \\ Catholic Theological Union, Chicago, IL 60615, USA; frohlich@ctu.edu
}

Received: 10 March 2020; Accepted: 14 April 2020; Published: 16 April 2020

check for updates

\begin{abstract}
In the period now being called the Anthropocene, the fatal vulnerabilities of the modern way of constructing selfhood are becoming ever more evident. Joanna Macy, who writes from a Buddhist perspective, has argued for the need to "green" the self by rediscovering its participation in ecological and cosmic networks. From a Christian perspective, I would articulate this in terms of an imperative to rediscover our spiritual personhood as radical communion in both God and cosmos. In this paper, "self" refers to an ever-restless process of construction of identity based in self-awareness and aimed at maintaining one's integrity, coherence, and social esteem. I use the term "person," on the other hand, to refer to a relational center that exists to be in communion with other persons. How - within the conditions of the dawning Anthropocene-can the tension between these two essential aspects of human existence be opened up in a way that can more effectively protect human and other life on Earth? This would require, it seems, harnessing both the self-protective and the self-giving potentials of human beings. The proposed path is to give ourselves over into the rhythms of the Spirit, being breathed in to selfless personal communion and out to co-creation of our refreshed selfhood.
\end{abstract}

Keywords: Anthropocene; selfhood; personhood; Spirit; Christology; breathing; self-loss; transformed self

\section{Introduction}

In the period now being called the Anthropocene, the fatal vulnerabilities of the modern way of constructing selfhood are becoming ever more evident. Joanna Macy, who writes from a Buddhist perspective, has argued eloquently for the need to "green" the self by rediscovering its participation in ecological and cosmic networks. (Macy 2007, chp. 14) From a Christian perspective, this can be articulated in terms of an imperative to rediscover our spiritual personhood as radical communion in the God who creates and participates in the entire cosmos. The proposed path to this renewal is to give ourselves over into the rhythms of the Spirit, being breathed in to selfless communion in divine personhood and out to co-creation of our refreshed selfhood. (Frohlich 2019)

After this Introduction (Section 1), the three main parts of this essay will be: Section 2, an exploration of how the psychological process of "selfing" has changed in the postmodern era; Section 3, an account of some ancient and contemporary developments in the Christian understanding of "personhood"; and Section 4, presentation of a perspective on the rhythms of the Spirit as offering hope for the greening of the self and the sustainability of the planet. 


\section{Basic Terminology}

"Self" and "person," as well as related words such as "soul" and "spirit," have different meanings in different systems of thought, so an initial clarification of usage is needed. In this essay, "self" refers to an ever-restless process of construction of identity based in self-awareness and aimed at maintaining one's integrity, coherence, and social esteem. Kenneth Schmitz wrote that the way of selfhood is that of "a resilient insistence upon an identity that preserves itself against others." (Schmitz 1991, p. 185) Thus, the "selfing" process is fundamentally self-centered (though not in a pejorative sense) and self-protective. It is as necessary to competent psychological function as having a skeleton is to walking. To fail to develop an adequately coherent and self-protective self is a severe pathology, and likely to result in behavior destructive to oneself and others.

I use the term "person," on the other hand, to refer to a relational center that exists to be in communion with other persons. This definition of personhood has arisen within the Christian tradition but has implications that are not limited to that milieu. The person loves, not for any extrinsic reason, but simply because being a person is to love. Personhood, then, is fundamentally relational and self-donative. Human infants are already persons. As parents attest, babies love, and call forth love, at the most profound level. It usually requires a lifetime of commitment to spiritual practice, however, to bring forth the full flowering of personhood in (relatively) selfless loving.

I say "relatively" because it is obvious that real human beings are always operating in both of these dimensions. Every human act deploys a complex dynamic of self-protection (selfhood) and self-giving (personhood). My purpose is by no means simply to denigrate the former and idealize the latter. It is, rather, to ask how-within the conditions of the dawning Anthropocene-this dynamic can be opened up in a way that can more effectively protect human and other life on Earth. This would require, it seems, harnessing both the self-protective and the self-giving potentials of human beings.

\section{Selfhood at the Dawn of the Anthropocene}

When exactly the tipping point into the Anthropocene era of decisive human influence upon all terrestrial cycles occurred is controversial, but I am looking upon it as the fruit of what we call "modernity." (Ruddiman et al. 2015; Ellis 2018) For our purposes here, the decisive shift in modernity was identified by René Descartes when he articulated the freedom of the human mind (the ego cogitans) in terms of disengagement from all material reality. One effect of this is to define the self as radically autonomous, rational, and world-dominating. This, in turn, justifies the unfettered technological manipulation of the natural world (including even our own bodies). It has been popular to say that we now live in a "postmodern" era, but it may be more accurate to say that we are in a transitional phase where the assumptions of modernity are in disarray while the struggle over what comes next is in full swing. Despite all the postmodern critique of both the style of selfhood and the often-destructive technological juggernaut that are characteristic of modernity, we are still fully immersed in living out their implications. (Giddens 1990; Harvey 1989)

\subsection{From the Autonomous Self to the Narrative Self}

A major component of what we call postmodernity has been a profound critique of the modern concept of selfhood. Today, at least in academia, the norm is to firmly reject the concept of the self as an autonomous interior entity that is transcendent to the body and the material world. Instead, the self is understood as an ongoing interpretive process conditioned by all aspects of the individual's embodied involvement in the world. In this postmodern view, the self is labile, dialogical, and (in a certain sense) "fictional," since it consists of an identity narrative that is selective and interpretive. (Eakin 2008; Teske 2017; McAdams 2006) Some go so far as to affirm a more radical "no self" perspective, somewhat along Buddhist lines-although even Buddhists are not fully in agreement with one another on the question of whether some kind of functional, though contingent, "self" exists on the psychological level. (Verhoeven 2010; Siderits et al. 2011) 
The consensus today, then, is to see the self as a story-telling process. The purpose of this "selfing" process is to interpret past, present, and imagined future in a way that maintains an inner sense of continuity, integrity, and meaningfulness while contributing to the fulfillment of one's social and material goals. Despite the aim of coherence and continuity, this story-telling process is actually highly responsive to changing relationships and circumstances. This means that there is likely to be more than one story line in process, and even within a given story line reinterpretation is constantly going on based on new circumstances or new goals.

In their book The Dialogical Self, Hubert and Agnieszka Hermans describe three types of "selfing": traditional, modern, and postmodern. Traditional selfing occurs in a social world perceived as unified, hierarchical, and authoritative. Insofar as the traditional self's storytelling mainly follows the cultural script, it is likely to maintain a deep sense of unity and "rightness." Modern selfing, shaped by an increasingly mechanized and anti-traditional world, tells its story in terms of the "sovereign self" whose inner core is separate from, and maintains power over, all that is other. The modern self emphasizes "personal goals, inner strength, overcoming resistance, personal achievement and heroism, masculinity, autonomy, future-orientation, progress, and control of the situation." (Hermans and Hermans-Konopka 2010, p. 89)

\section{2. "Selfing" in Late Modernity}

While both of these styles of selfing still exist, at the dawn of the Anthropocene it is what the Hermans call the "postmodern" style that is increasingly prevalent. In this style, centerless flux, fragmentation, and superficial play are the norm. A number of sociologists and psychologists have written about the extreme difficulty of constructing a viable form of selfhood under postmodern conditions. (Lifton 1993; Giddens 1997a; Gergen 2000) The most dominant challenge is that life in contemporary societies is characterized by a "swirling sea of relations" (Turner 2008, p. 44) that constantly change at a staggering rate. Daily life is saturated by media unceasingly spewing forth a cacophony of often-superficial stories that do not hang together or collectively point toward anything worthy of a life commitment. Meanwhile, everything_including the most intimate aspects of our identities, our relationships, and even our spirituality - has been commodified. Well-funded experts in "branding" work day and night to persuade us that if only we buy this particular clothing item, or this mood-enhancing dietary supplement, or this slick new spiritual practice, we will find happiness and success. Their goal, as sociologist Bernard McGrane puts it, is to convince us that "life becomes radiant through consumption." (Stein 1999)

In Kenneth Gergen's view, late modern culture has created homo optionis. To be human in this culture is defined by having at each moment a staggering array of identity options, among which we must constantly pick and choose. People can flit in and out of vast numbers of ever-shifting and often "virtual" relationships with people and groups around the world. Gergen terms this the "saturated self," whose efforts to maintain a coherent identity are overwhelmed by the number and incompatibility of invitations to self-investment that impinge upon it. He wrote: "As social saturation adds incrementally to the population of the self, each impulse toward well-formed identity is cast into increasing doubt; each is found absurd, shallow, limited, or flawed by the onlooking audience of the interior." (Gergen 2000, p. 73)

Some recent books give depressing portraits of how this postmodern culture shapes the self-making of young people in the US today. In Generation Me, Jean Twenge describes how child-raising styles since the 1990s have encouraged many young people to internalize a story in which being highly successful and wealthy is an option to which they are entitled. Any evidence to the contrary-e.g., the critical remarks of a teacher or work supervisor-is boomeranged back as a fault in the criticizer. (Twenge 2014) Meanwhile, seeking work, as well as searching for dating partners, requires day-and-night attention to building one's "brand" on social media. Twenge's research finds that as the anxiety to focus intensively on building one's personal brand grows, concern about politics, civic involvement, and environmental issues declines-and more so with each younger cohort. She also details how young people have 
completely tossed out the sexual mores of previous generations, in many cases preferring multiple "hookups" with no intention whatsoever of intimacy or ongoing relationship. This style of selfing seems to combine over-investment in receiving affirmation from large numbers of virtual relationships with a relative incapacity for the concrete give-and-take of committed face-to-face relationships.

In Kids These Days, Malcolm Harris describes how the system of capitalism has re-engineered all of life in view of increasing profits. He writes: "The growth of growth requires a different kind of person, one whose abilities, skills, emotions and even sleep schedule are in sync with their role in the economy." (Harris 2018, p. 5) If a young person internalizes these skills sufficiently to make it into college, they take on massive debt with the promise that the purchase of education is the guarantee of success. But once they graduate, they learn that the twenty-first century work world is brutal, often demanding a constant search for low-paying "gigs" without regular hours or health insurance. Anne Helen Petersen calls this "the burnout generation" because they are never offline-meaning by this not only the literally ever-present phone, but the never-ending internalized demand to be doing "something" to enhance one's brand and optimize one's possibilities. (Petersen 2019) A style of selfing maximized for capitalistic profit is neither satisfying nor, ultimately, sustainable for persons or communities.

\subsection{Ultimate Vulnerability: The Failure of the Self-Protective Function of Selfing}

Much more could be said, but the question these studies raise is whether the type of selfhood emerging within this late modern world has any possibility of sustaining a future for humanity. Self-making is meant to be self-protective, but in its current form it is failing to fulfill the function of protecting human life and legacy beyond the present generation. The fatal vulnerability remains that of modernity: the separation of the self from its integral connection with the natural world. What seems to be happening at the dawn of the Anthropocene is that both separated partners-Earth, and human selves-are spiraling in tandem towards destructive, out-of-control "overheating." For the Earth, the spiral of overheating is intensifying pollution and climate change. For humans, the spiral of overheating is a style of selfhood that has lost touch with both inner and outer sources of meaning, stability, and resilience. These two spirals are feeding each other, with increasingly deadly consequences.

The question at hand is whether there remains any possibility that this dawning Anthropocene era of deep human intertwinement with Earth processes could still give birth to another possibility-one in which we humans reclaim the self-protective value of recalibrating our self-making in responsiveness to the Earth processes with which we are, in fact, completely interdependent. This is what Macy called "the greening of the self," and it appears to be the only scenario in which our Earth can be sustained as a habitat for humans (and vast numbers of other species) for more than a few more decades.

\section{Perspectives on Personhood}

A positive answer to the above question, I believe, will require attention to a dimension even more profound than selfhood, namely "personhood." As will be evident from what follows, I write about personhood from the perspective of a Christian theologian. I want to emphasize, however, that my intent is not to restrict the value of the insights only to those who are of the Christian faith. The approach to personhood that has developed within Christian theology may have something important to offer when placed in dialogue with the quite different approach that predominates in many current philosophical discussions.

\subsection{Early Christian Understanding of Personhood}

In Greek, "person" is prosopon, which seems to derive from terms meaning "face to face" or "facing toward." It came to be associated with the masks worn in Greek theatre, in which humans wrestled tragically to enflesh freedom and identity in the face of the unity and necessity of the cosmos. (Papantoniou 2004, pp. 61-62) The early connotations of personhood, then, include face-to-face relations in which individual agency is exercised. From the time of Tertullian (3rd c. CE), persona (the 
Latin translation of prosopon) was used in Western Christianity to characterize God in the doctrine of the Trinity. Eastern thinkers, however, preferred the term hypostasis or "concrete individual reality" since they saw prosopon/persona as lacking ontological content. Eventually, the two terms came to be identified with each other and to condition one another. The theological definition of "person" as a concrete, individual reality known only within a "face to face" relationship of love was coming to be born.

It was within the fifth and sixth century debates over how to understand who Jesus was in relation to both humanity and divinity, however, that the most significant theological developments of the concept of personhood emerged. Many Christological theories were being presented, some stressing the dynamic unity of Christ's consciousness and agency while others fiercely argued that it is essential to affirm the "twoness" of both human and divine elements. In 451, the First Council of Constantinople famously attempted to resolve these debates by declaring that Jesus had two natures (human and divine), which came together in one prosopon ("persona" or self-presentation), and one hypostasis (concrete individual). Another Council in 527 would make explicit the affirmation that the one "person" of Christ is the divine Word of God.

As Brian E. Daley has detailed, at its inception the Chalcedonian formula was a rather hastily composed compromise which was, no doubt, only superficially understood by many of the Council Fathers who approved it. Daley argues that the formula's composers did not intend it as a sweeping speculative theology of the relation between God and the world (as it has subsequently been interpreted to be), but rather as a set of loose boundaries for orthodoxy. (Daley 2016) Indeed, in the immediate aftermath, this formula actually aroused more controversy rather than resolving the issues as the Council's organizers had hoped. Despite this rather shaky start, the formula of "two natures, one person" became more and more embedded in orthodox Christian tradition as a foundation stone of Christology. Over the subsequent 1600 years of theological thought, its interpretation has been repeatedly developed and deepened in dialogue with the prevailing insights of each era.

\subsection{Zizioulas and the Ontology of Personhood}

Most recently, the Orthodox prelate Jean Zizioulas has argued in favor of what he calls an "ontology of personhood." He does not define personhood primarily in terms of consciousness or communion, but rather in terms of free self-donation. Zizioulas builds his argument on the assertion that the Cappadocians (4th c. CE), whose thought lies behind the Chalcedonian formula, had an insight that radically redirected the Greek philosophy of the time. For the Greeks, only two ontologies were possible: monism, in which "the being of the world and the being of God formed ... an unbreakable unity"; or gnostic dualism, in which there was a radical gulf between God and the world. (Zizioulas 1985, pp. 17-18) Early Christians clearly rejected dualism as incompatible with scriptural revelation, but monism was problematic as well because of the way it eliminates the freedom of God in relation to the created world-and of the created world in relation to God.

The new insight of the Cappadocians, according to Zizioulas, was that God is not "substance" but "person." The most central characteristic of personhood is that persons exist only in a free and mutual relationship of love with other persons. (LaCugna 1991, pp. 289-92) As divine person, God freely creates the world and freely enters into personal relationships with creatures. On this basis the Cappadocians also developed the doctrine of the Holy Trinity as one divine nature in three persons-that is, one God differentiated by nothing except relations of complete mutual self-giving. This notion of subsisting relations was further clarified in the thirteenth century by Thomas Aquinas. The Trinity, then, is characterized by "total and undiminished self-donation; absolute orientation to the other." Personal giving and receiving "is the very being of Begetter and Begotten." (Schmitz 1991, p. 200)

The challenge of articulating this view of personhood is that, since divine relationality is not reducible to any created manifestation, any discussion of it ultimately has to point to an essentially apophatic dimension. This challenge becomes acute in attempting to explain the core Christological distinction of "two natures" and "one person." If both "nature" and "person" were identified as 
involving contingent aspects of the human individual, an implication would be that central aspects of human nature (e.g., natural capacities for freedom, knowledge, love) would have to be removed from Jesus, so as to be substituted by divine personhood. Theologians insist, however, that divine personhood does not substitute for any aspect of human nature, which remains complete and fully functioning. Since divine personhood is not an aspect of created reality, but rather can only be indicated in apophatic terms, it is able to operate in and through every aspect of Jesus's humanity without in any way disrupting the ongoing natural operation of human functioning. In the context of this essay, an implication of this is that personhood does not eliminate or replace the natural and contingent process of "selfing."

\subsection{The Personhood of Human Beings—and Others}

Based in the definition of personhood as capacity for free relations of mutual self-giving, early Christian thought went on to affirm human beings as also having our most fundamental reality and dignity as "persons." The intrinsic relationality that characterizes the divine persons in the Trinity is also central for human persons insofar as human fulfillment is destined to be found in the freely-entered communion of human beings with each other and with God. Human persons, then, are free, capable of loving, and fundamentally designed for mutual intimacy. Persons are never static or reified beings who can be known objectively, but rather are intrinsically relational creatures who can only truly be known relationally. The Christian view is that this is true from our beginning in receiving life as a gift from a personal God to our end in fulfilled communion with divine and human persons.

In the context of the Anthropocene and the acute ecological crisis that accompanies it, the attribution of personhood exclusively to human beings is being challenged. If personhood is the most central reality of the Creator-God, why presume that it is shared only with human creatures and not with others? Many indigenous cultures have presumed the opposite, affirming that personhood can be exhibited by animals, plants, geographic features, and even stones. In a much-discussed essay, anthropologist Irving Hallowell recounts asking an Anishinaabe elder about whether all the stones around them are alive. The elder answered "No, but some of them are." (Hallowell 1960, p. 24) Exploring this in depth, Graham Harvey finds that in this indigenous perspective, to be a person is to be in relationship in a respectful and reciprocal way. The most basic quality of personhood is to know when and how to participate in gift-giving. Thus, some stones, animals, plants, etc. are persons-but some may not be. In fact, in this perspective, the same is true of human beings: we have to become persons though concrete and appropriate participation in relationships. Thus, Harvey observes that when Europeans first met Native Americans the Europeans asked, "Are they human?" But the Native Americans' implicit question was, "Are they persons?" (Harvey 2017)

In her book Spirit Unleashed: Reimagining Human-Animal Relations, Anne Benvenuti draws on both her own experience and a wide array of contemporary scientific and philosophical literature to argue that the assertion of a radical distinction between human and animal "souls" is not only false, but deadly for both humans and animals. (Benvenuti 2014) Over twenty years ago, Langdon Gilkey argued that all creatures should be seen as sharing in some vestigial way in the "image of God"-a phrase from Genesis 1:27 that has traditionally been assumed to apply only to humans. (Gilkey 1993, pp. 175-92) In a recent book, Franciscan theologian Daniel P. Horan reviews a variety of approaches to the question of human exclusivism (e.g., that only humans are made in the image of God) and concludes by proposing a Scotist approach that prioritizes the unique, unrepeatable, and particular character of each and every created entity. In his view, this relaxes the problem of defining "natures" and placing them in hierarchical order, with human nature nearest to God; instead, every creature has its own unique and individual relationship with God. (Horan 2019, chp. 3)

Building on all these ideas, my proposal is to explore the possibility that if "personhood" is defined not in terms of a nature or substance, but as relationality itself, it can be seen as the image of God that forms each creature in its own unique way. It is evident that every creature is utterly dependent on its relations, even though the specific structure of how this plays out is unique. The indigenous insight 
described by Harvey is that many types of creatures (not only humans) may participate in relations in ways that affirm universal kinship and build communities of love and respect. This is evidence of some level of participation in personhood.

This raises the question of whether, if some humans do not behave in an appropriate personal manner by building relationships of kinship and communion, they may not qualify as "persons." Christian tradition has strongly resisted such a conclusion, affirming that all human beings, regardless of their virtue or sinfulness, are persons and so are intrinsically worthy of being related to with love and respect. In the context of modern philosophical thought, however, when the predominant definition of personhood typically is something along the lines of Locke's "a thinking intelligent being, that has reason and reflection, and can consider itself the same thinking thing, in different times and places," (Quoted in Rowlands 2016; from Locke 1961, p. 280) it has been difficult to see how infants or those with severe intellectual disabilities could qualify. Defining personhood in terms of relationality relieves this impasse, since affective and embodied relationship does not require advanced cognitive abilities. (See Brown 1998. Brown applies a similar argument to the question of "soul.") At the same time, this approach necessarily opens the door to considering at least some non-human beings as participating in personhood.

\subsection{Personhood as Participation in Divine Personhood}

It is important to recall that personhood is not to be understood as a "deeper level" of selfhood, nor is it a distinct identifiable "place" or "function" within natural entities. Rather, it is an apophatic participation that potentially can operate in and through natural created life. In my view it is, in fact, the participation of creatures in the personal reality of God. The personal God freely embraces all of creation in loving relationship, and each creature is formed into some degree of capacity to mediate that personhood. If all creatures share in some way in divine personhood, can we still say that humans are so constructed as to be capable of enfleshing the divine character of personhood more completely or more perfectly than other kinds of creatures? This is a point to be debated, but what matters far more- especially at this crisis point in the history of life on Earth-is that we humans actually find a way to maximize our enfleshment of personhood, to whatever degree we are capable.

In my view, the potential to be a mediator of divine loving personhood is not contingent upon having faith in God or belief in specific doctrines; it is simply how we have been created. Every human being is born to give and receive personal love, to weave bonds of community, and ultimately to be welcomed into union with God. It is evident, however, that this capacity to love is concretely manifested to greater and lesser degrees in different individuals. I would propose that the difference may be located in each one's individual history of the development of selfhood. There are some people in whom trauma or other pathologies has led to a distorted self-protectiveness that seems to so profoundly obscure any capacity to give or receive love that it may require great conviction even to believe that they have potential to manifest relational personhood. And there are others in whom the story of the self is permeated with such generosity, kindness, and radiance that one barely notices any self-protective tendencies, as one is so quickly drawn into a sense of loving relationship with the person. Most of us, of course, fall somewhere in between these two more extreme possibilities.

The challenge at the dawn of the Anthropocene is that our very survival as a species is calling for a vastly broadened and deepened level of relationality—one which reaches out to interact respectfully and appropriately with all other species, geological processes, and the Earth itself by including them as our "kin." The survival of our species, and of the Earth as a richly biodiverse ecosystem, needs us to be persons-that is, creatures defined by, and living to the full, our capacity for self-giving love-in a fresh and profound manner. Yet, in this moment of Earth crisis, the predominant style of human self-making instead seems to be tending toward superficiality, fragmentation, and-frankly-narcissism. Is it possible for such weak and broken selves to rediscover and develop the relational potential of their personhood? 


\section{The Revitalizing Rhythms of the Spirit}

Obviously, the answer to the above question is complex. Sometimes weakness and vulnerability can create openings for a positive breakthrough to renewed and deepened strength, while in other cases they only lead to descent into increased chaos and devastation. My goal in this section is to describe how the relational personhood of God, in the person of the Holy Spirit, strives always and everywhere to enhance the possibility of the former.

\subsection{The Rhythm of "Lost" and Renewed Selfhood}

A good place to begin is with the gospel report that Jesus said, "The one who saves their life will lose it, and the one who loses their life for my sake shall save it." (Matthew 16:25; Luke 9:24.) The word here translated as "life" is actually psyche, which could equally be translated as "self." But this saying is hard to interpret. Is Jesus saying that one should actually eliminate, or radically minimize, all manifestations of our self-protective selfhood? Those who try this usually end up bringing worse evils not only upon themselves, but upon others as well. Selfhood can no more be eliminated from our psychological life than the skeleton can be cut out of the body. A better interpretation, in my view, is that "losing" the self means being open-we could even say, vulnerable-to significant change in the embedded story of the self. The question is, how does truly positive change in the story of the self happen - that is, change toward a style of selfhood that allows the radiance of personhood to operate more freely?

My proposal is that it happens through the rhythms of the divine Spirit who breathes in all of creation. (These ideas are developed more fully in Frohlich 2019) "Breathing" is, of course, a metaphor, since divine Spirit is not operating in the same dimension as any form of created movement. Divine Spirit is better compared to a non-material field (something like gravity or magnetism) that moves objects without itself having material presence. The in and out breathing of the Spirit manifests the ever-present divine invitation both to abandon oneself completely in radical communion with God, and to emerge with a renewed self that is more fit for collaboration with God in mission. Just as breathing in and breathing out require one another, and neither can occur unless a rhythm is established between them, so the Spirit works in human life through the necessary and repeated rhythm of "losing" and renewing the self.

The first movement of the rhythm occurs as the Spirit breathes us in to an ecstatic communion of love with God in which our relational personhood blossoms in joy. While sometimes such an experience can be intense and prolonged, more often it is like a glimpse or a hint that is gone before one even begins to grasp what has occurred. When I have asked people to write about a "spiritual experience" that they have had, it is this sort of moment that most recount. It may occur in the context of prayer or religious ritual, of course, but it is just as likely to come out of nowhere in the midst of ordinary life. No one can program such a moment, although many kinds of spiritual practice are designed to awaken our desire for such communion and to shift our attention toward its possibility. I call this the "way of emptiness," because the communion that we glimpse is fundamentally apophatic; that is, it is beyond capturing in any words, images, practices, or feelings. It is an event in which our communion in personhood shines forth in its fullness-even if only for the briefest of moments.

I call the second movement of the rhythm of the Spirit, in which the self is reconstructed afresh, "the way of remembering." This plays on both the role of memory, and the alternate meaning of "re-membering" or making a new whole. Since the story of the self is founded in an interpretation of memories, a renewed story requires a revised interpretation of what has happened in one's life, as well as of the potential this creates for a desired future. Even a moment of glimpsing the infinite, overflowing love that constitutes one's personhood-whether experienced as joy, wholeness, cosmic oneness, or radical love-can change the story of one's life. When someone is asked to recount the story of their most significant choices and conversions, such events will typically be found in or near the nodes of change. 
Unfortunately, change in the deeply embedded patterns of our selfhood is never easy, and many forms of resistance waylay our ability both to abandon ourselves and to allow ourselves to be re-membered afresh. For the traditional style of self, resistance perhaps most often takes the form of a kind of rigidity based in a narrow set of cultural expectations for how one ought to live a meaningful life. For the modern style of self, resistance may be withdrawal into the fortress of one's presumed autonomy and domination. In the postmodern self-style, resistance may be the unwillingness to take anything seriously - even the looming devastation of the planet and the potential demise of our own species.

\subsection{Hope for the Greened Self}

The Spirit has its ways, however. My conviction is that the Spirit is always and everywhere breathing in and around us. We have been created by and for this rhythm of both self-giving personhood and self-protecting selfhood. Those who write about how to get people to vote or act for ecological causes have pointed out that it is usually more effective to focus first on how the proposals will benefit them and their children and grandchildren-in other words, to appeal first to the self-protective self. The much deeper change that the dawn of the Anthropocene urgently demands, however, will require also awakening the self-giving personhood that is our most profound human heritage. In this emerging Anthropocene era, it is more imperative than ever that human beings find the path to living as responsive and responsible kin within a sustainable Earth community.

How can this come to be? Here we must return again to consider the "vulnerability" that is identified in the title of this essay, as well as others in this symposium. The self is instinctively self-protective because, like every created thing, it is intrinsically vulnerable: that is, it is constantly subject to wounding, disintegration, and death. But this vulnerability can have two potential outcomes. One potential of vulnerability is that instability may catastrophically compound into spiraling levels of chaos, violence, and fragmentation. The paradox of the instinct of self-protection is that if it is left on its own without the complementary movement of self-giving, the ultimate result is self-destruction. This is what we fear when we speak of the negative vulnerability of the postmodern style of selfing, with its tendencies to narcissism and other pathologies.

The alternative potential of vulnerability, however, is what psychiatrist Kazimierz Dabrowski calls "positive disintegration": the fragmentation that necessarily precedes the emergence of integration at a higher level. (Dabrowski 2016) The positive vulnerability of the postmodern style of selfing could be that it is far more open to change than were previous styles. Still, this change will only be truly "positive" when the rhythm of the Spirit is fully engaged. I am convinced that the Spirit offers every human being, regardless of their beliefs and circumstances, invitations to participate in the radical communion of love that has borne us into being. In those often-brief glimpses, one realizes, if only for a moment, what it means to be released beyond self into joyfully self-giving personhood. The self is "greened" when we open ourselves to such moments and take on the challenge of breathing with the Spirit, who will not neglect to protect our truest self while drawing us ever-deeper into the even more profound truth of our personhood.

Funding: This research received no external funding.

Conflicts of Interest: The author declare no conflict of interest.

\section{References}

Benvenuti, Anne. 2014. Spirit Unleashed: Reimagining Human-Animal Relations. Eugene: Cascade Books.

Brown, Warren S. 1998. Cognitive Contributions to Soul. In Whatever Happened to the Soul?: Scientific and Theological Portraits of Human Nature. Edited by Warren S. Brown, Nancey C. Murphy and H. Newton Malony. Theology and the Sciences. Minneapolis: Fortress Press, pp. 99-125. 
Dabrowski, Kazimierz. 2016. Positive Disintegration. Anna Maria: Maurice Bassett.

Daley, Brian E. 2016. Unpacking the Chalcedonian Formula: From Studied Ambiguity to Saving Mystery. The Thomist 80: 165-89. [CrossRef]

Eakin, Paul John. 2008. Living Autobiographically: How We Create Identity in Narrative. Ithaca: Cornell University Press.

Ellis, Erle C. 2018. Anthropocene: A Very Short Introduction. New York: Oxford University Press.

Frohlich, Mary. 2019. Breathed into Wholeness: Catholicity and Life in the Spirit. Catholicity in an Evolving Universe. New York: Orbis Books.

Gergen, Kenneth J. 2000. The Saturated Self: Dilemmas of Identity in Contemporary Life. New York: Basic Books.

Giddens, Anthony. 1997a. Modernity and Self-Identity: Self and Society in the Late Modern Age. Stanford: Stanford University Press.

Giddens, Anthony. 1990. The Consequences of Modernity. Stanford: Stanford University Press.

Gilkey, Langdon. 1993. Nature, Reality, and the Sacred: The Nexus of Science and Religion. Theology and the Sciences. Minneapolis: Fortress Press.

Hallowell, A. Irving. 1960. Ojibwa Ontology, Behavior, and World View. In Culture in History: Essays in Honor of Paul Radin. Edited by Stanley Diamond. New York: Columbia University Press, pp. 19-52.

Harris, Malcolm. 2018. Kids These Days: Human Capital and the Making of Millennials. New York: Back Bay Books/Little Brown and Company.

Harvey, David. 1989. The Condition of Postmodernity: An Enquiry into the Origins of Cultural Change. Cambridge: Blackwell.

Harvey, Graham. 2017. If Not All Stones Are Alive ... : Radical Relationality in Animism Studies. Journal for the Study of Religion, Nature \& Culture 11: 481-97.

Hermans, Hubert J. M., and Agnieszka Hermans-Konopka. 2010. Dialogical Self Theory: Positioning and Counter-Positioning in a Globalizing Society. Cambridge: Cambridge University Press.

Horan, Daniel P. 2019. Catholicity and Emerging Personhood: A Contemporary Theological Anthropology. Catholicity in an Evolving Universe. Maryknoll and New York: Orbis Books.

LaCugna, Catherine Mowry. 1991. God For Us: The Trinity and Christian Life. San Francisco: HarperSanFrancisco. Lifton, Robert Jay. 1993. The Protean Self: Human Resilience in an Age of Fragmentation. New York: BasicBooks.

Locke, John. 1961. An Essay Concerning Human Understanding. London: J.M. Dent and Sons.

Macy, Joanna. 2007. World as Lover, World as Self: Courage for Global Justice and Ecological Renewal. Berkeley: Parallax Press.

McAdams, Dan P. 2006. The Problem of Narrative Coherence. Journal of Constructivist Psychology 19: 109-25. [CrossRef]

Papantoniou, Anthony. 2004. The Mystery of the Human Person in Orthodox Theology: Some Reflections. Phronema 19: 59-77.

Petersen, Anne Helen. 2019. How Millennials Became the Burnout Generation. BuzzFeed News. January. Available online: https://www.buzzfeednews.com/article/annehelenpetersen/millennials-burnout-generation-debtwork (accessed on 15 April 2020).

Rowlands, Mark. 2016. Are Animals Persons? Animal Sentience. 10. Available online: https: //animalstudiesrepository.org/animsent/vol1/iss10/1/ (accessed on 15 April 2020).

Ruddiman, William F., Erle C. Ellis, Jed O. Kaplan, and Dorian Q. Fuller. 2015. Defining the Epoch We Live in. Science 348: 38-39. [CrossRef]

Schmitz, Kenneth L. 1991. Selves and Persons: A Difference in Loves? Communio 18: 183-206.

Siderits, Mark, Evan Thompson, and Dan Zahavi, eds. 2011. Self, No Self? Perspectives from Analytical, Phenomenological, and Indian Traditions. New York: Oxford University Press.

Stein, Todd. 1999. Zen Sells: How Advertising Has Co-Opted Spirituality. Lion's Roar: Buddhist Wisdom for Our Time. November. Available online: https://www.lionsroar.com/zen-sells-how-advertising-has-co-optedspirituality/ (accessed on 15 April 2020).

Teske, John A. 2017. Knowing Ourselves by Telling Stories to Ourselves. Zygon: Journal of Religion E Science 52: 880-902.

Turner, Léon. 2008. Theology, Psychology and the Plural Self. Burlington: Ashgate. 
Twenge, Jean M. 2014. Generation Me: Why Today's Young Americans Are More Confident, Assertive, Entitled-and More Miserable than Ever Before, rev. and updated ed. New York: Atria Paperback.

Verhoeven, Martin J. 2010. Buddhist Ideas about No-Self and the Person. Religion East E West 10: 93-112.

Zizioulas, John D. 1985. Being as Communion: Studies in Personhood and the Church. Crestwood: St. Vladimir's Seminary Press. 